\title{
Research on the Construction and Development of Smart Hotel from the Perspective of Serving Customers
}

\author{
Xu Xia \\ Guilin Tourism University \\ Guilin, 541000, China
}

\begin{abstract}
Under the background of the strong development of smart tourism, electronic information technology has been validly integrated with hotel service industry. With the upgrading of hotel management system and the intelligence of individual service, smart hotel has become one of service development directions in current tourism industry, and the construction development and research about smart hotels are the new topics that hotel managers must face. This paper starts from the characteristics of smart hotel, puts forward suggestions for the construction of smart hotel from the perspective of customers considering four aspects, including convenience, comfort, security and comprehensiveness, and provides certain reference value for the future development of smart tourism.
\end{abstract}

Keywords-Smart hotel; Serving customers; Development suggestions

\section{INTRODUCTION}

Smart hotel is an important part for the development process of smart tourism and smart city, and it is a management mode different from the general information system or engineering core technology. The smart hotel and traditional hotel have certain differences in internal management construction, and the smart management of smart hotel is the smart promotion for the service of various projects in the hotel through utilizing electronic information technology in combination with the hotel service project, and it introduces "artificial intelligence, and service concept", and can provide brand new intelligent feelings to customers. Currently, domestic research about smart hotel has been stepped into hot exploration period, and in this era when electronic information technology is widely used, hotel management intelligence will become an inevitable direction and new topic for the future hotel development [1]. Thus, hotel management can only truly create smart hotel products through fully realizing the future development direction of smart hotel, studying from the perspective of customers, conducting smart service design based on the perspective of customers, starting from the perspective of customers, thinking for customers and reasonably utilizing smart technologies.

Author: Xia Xu (1978- ), women, born in Nanning in Guangxi Province, Master's degree, Senior economist, and research area: Hotel management.

\section{THE RISE OF SMART HOTELS}

Along with the fast development of tourism industry and the hotel industry, there are more and more channels selected by people for tourism, and the demand for resort hotels will also be increased in multiples, and the fierce competition of hotel brands have made customers' expectations for hotel service increasingly high. Under the big background of Chinese economic transformation and consumption upgrading, the future years will be the golden period for accelerating the development of hotel industry, and smart hotel will gradually become the second "home" for modern people to travel.

Under the demand of supply-side reform, traditional hotels will gradually lose their competitive advantages considering the competition of the internal decoration of hotels, the quantity of guest room, the room facilities the quality and room price, etc., which have made insiders constantly seek for some new operation methods considering how to improve hotel sales, enhance service quality, search for the decrease of management cost and improve customers' satisfaction degree, so as to reinforce the core competitiveness of hotels, of which the most valid means is to apply advanced informatization technology within a large scale. It is requested to reform the competition mode and operation management mode of hotel industry in traditional meanings, and then win the new competition advantages. Thus, the future competition direction of the hotel industry will be mainly carried out considering intelligence, individuation and informatization, and smart hotels have sprung up quietly.

Smart hotel has sound hotel intelligent system, and can realize the information service technology through internet informatization, digitalization and other technical means, so as to realize the objective of saving operation cost for hotels, reinforcing customers' experience degree, and improving employees' work efficiency.

As the important means for the industrial structure adjustment and upgrading of hotel industry, the construction of smart hotels should change concepts, regard sustainable development as the starting point and destination, innovate and develop the operation management mode of hotels, and rebuild hotel business procedures. Smart hotels have not only realized resource intension, low carbon environmental protection, but 
also decreased hotel operation cost, improved the economic benefits of hotel, and promoted the comprehensive promotion of economic, social, ecological and cultural values, and it is necessary road for the sustainable development of the hotel industry.

\section{THE DEVELOPMENT CHARACTERISTICS OF SMART HOTEL}

\section{A. Smart service}

Smart service is the core service for smart hotels, and is also the main objective for the development of smart hotels. The smart hotel service refers to using the combination of electronic information technology and hotel service project, to improve the hotel service quality, reinforce customer experience, meet customers' demand, and improve the overall image of hotels. Currently, smart hotel service projects include: parking lot management system, petrol management system, antitheft alarm system, closed circuit television monitoring system, elevator safety and operation monitoring system, and guest room smart management system. With the progress of material conditions, this part has gradually improved the requirements of customers for intelligence.

\section{B. Smart management}

The smart management of smart hotels refers to using electronic information technology to promote the smart service of the hotel. The promotion change of smart service is mainly oriented to various service businesses of the hotel and is one of the important means for meeting customers' satisfaction degree, and also one of the important factors reflecting hotel service quality. Currently, the hotel industry of our country is still in the initial period considering the smart service management, and the management project for the smart hotel during the current period mainly includes one-stop registration and check-in service system, the smart management of hotel guest rooms, and the backstage management of hotel operation.

\section{The DeVElopment Status of SMART Hotels AT HOME AND ABROAD}

The overseas researches about smart hotel are based on the development of informatization technology, and smart hotels were originated from the research about smart buildings. Along with the constant improvement of digitalization level, smart buildings have become increasingly high-efficient, energy-saving and comfortable, and the development of smart buildings has been extended to the development of the hotel industry, and then incurred the transformation of smart hotels. The application of overseas smart hotels can be traced back to the year of 2006 at the earliest when Cobono Mountain Resort of Pennsylvanian, America introduced "RFID" system; in 2009, City Center Lasvegas Hotel in Las Vegas, America was established, and the hotel applied smart system to set personal preferences of customers as the procedure mode, and improve the accommodation experience[2] [Research on the Construction and Application of the Smart Hotel Construction Evaluation Index System, Xiaoxian Ren-Thesis for Master Degree in Hebei Normal University]; since then, the development and application of overseas smart hotel for the new generation of information technology have been constantly improved, of which the development in America, Korea, Singapore and other countries is relatively fast.

The development of domestic smart hotels is relatively later than that abroad, and under the big environment of information technology wave sweeping the world, along with the R\&D of hotel smart house control system, the hotel intelligence has been gradually updated, more and more hotels would like to accept new management concept and operation concept, and apply smart house control system to cater for the reform of hotel industry during the informatization era.

Currently, smart hotels have become the main operation objective of high-end hotels. Hotels with higher similar level (four-star and five-star level) have been set with some science and technologies, such as digital television, and internet information query considering the construction standard as per the provisions stipulated in the Division and Evaluation of Hotel and Restaurant Star Level (GBT14308-2011) [3].

\section{THE NECESSITY OF DEVELOPING SMART HOTELS}

\section{A. Smart hotel is an inevitable product of the development of smart tourism}

Along with the fast development of modern technology, the development of smart tourism has brought new contents; as one of the three pillars for the tourism industry, there are also huge changes in the hotel industry. Since there are many hotels of various types, how to keep the hotel market in fierce competition is an important work for all hotel managers. Hotel products should be upgraded, and updated, and adopt intelligent and humanized service mode, so as to change the hotel operation mode in essence. Such new service mode can not only largely save the operation cost of the hotel, but also sufficiently display the hotel image and the products provided thereby, and can be good for the in-depth development of hotel products and increase the economic benefits of the hotel, so smart hotel is the inevitable product for the development of smart tourism.

\section{B. Smart hotel is a platform for providing all kinds of information to customers}

Since smart hotels have integrated artificial intelligence, the internet of things, communication, cloud calculation and other technologies into the hotel management service system, smart hotels have built a comprehensive service platform through these high technologies. On the platform, it contains various kinds of customers' information considering tourism and urban public products and service, and customers can query and search for the required information merely through the smart terminal system of the hotel, and largely meet their demands. The smart hotel platform is also a platform that can fully display the image of the hotel and provide products; it can promote the in-depth development of hotel products, and further reinforce the comprehensive profits of hotel resources. 


\section{Smart hotel is an inevitable choice to meet the diverse needs of customers}

At present, domestic and overseas tourism demands are largely increased, and various tourism demands are different, so how to meet the diversified demands of customer can be the important problems commonly faced by various hotel managers. Traditional management and operation modes cannot well solve this problem, and the only requirement is to use modernized scientific and technical means for innovation as per the actual development conditions, change and upgrade hotel products, analyze and integrate various kinds of customer information, and provide the system service that can meet the demands of customers. The construction of smart hotel is a new transformation of hotel industry, and smart hotel is also an inevitable choice to meet the diversified demands of customers.

\section{Suggestions on Building SMart Hotels From the PERSPECTIVE OF CUSTOMERS}

The measurement standard of hotel service is the satisfaction degree of customers, so from the perspective of customers, it is requested to stand in the pace of customers, and consider the demand of customers, so as to find out the inspiration for building smart hotels. Currently, as can be seen from the current status of customer demand in our country, the demand for hotels is mainly reflected in: convenience, comfort, security and comprehensiveness, so the construction of smart hotels should follow these demands of customers, and should be conducted from the following layers:

\section{A. Convenience}

Enlarge the construction strength of smart hotels, realize the unification of electronic, informatization and intelligent functions of smart hotels, and largely improve the convenience of customers. Smart hotels should realize the full coverage of wireless broadband network. Customers can conveniently use mobile phones, computers and other terminals to connect to the internet through wireless mode in the hotel, and can make calls through computer, smart phones, and mobile tablet computer at any time, and build official comprehensive information platform. When customers arrive at the store, they can connect to the official comprehensive information platform of the hotel, enter into the hotel check-in and checkout system as well as the check-in registration of the hotel, and independently handle check-in; after completing the consumption, they can also re-log in the check-in and checkout system, and directly handle check-out procedures. During the period at the hotel, it is also applicable to fill in relevant information through the official comprehensive information platform of the hotel, and handle invoice, mailing, payment and other businesses [4].

\section{B. Comfort}

Hotels are the houses of travelers when they are away from home; in order to let customers feel the home-like comfort feelings, smart hotels should meet the diversified demands of customers to the utmost extent, and strive to realize the maximum comfort of hotel service facilities. When checking in, guest room service will be provided to customers as per their characteristics and preferences, to make them feel home-like comfort and intimate service.

Besides, smart hotel service project should also be equipped with the following functions, such as: (1) possessing the official comprehensive information platform owned by the hotel, to provide the newest information about the hotel; (2) through the official information platform of the hotel, providing customer service, message leaving, leasing, and exchange interaction information for customers; (3) the hotel charging system can provide real-time consumption information of all departments in the hotel, and let customers know about their bill details in time; (4) in the restaurant, it is applicable to conduct smart ordering service through IPAI.

\section{Security}

The security of smart hotel has been largely improved on the basis of traditional hotel. Firstly, hotels can provide customized gate card for customers, and configure with smart elevator system. Customers in the hotel can only use the elevator with the card, and smart elevator system can automatically identify the room card information of the customer and then land at the floor of the customer. After the elevator automatically lands at the floor of the customer, it can guide customers to the position of the room along the aisle. Besides, it can also validly present the unnecessary elevator operation energy loss, and realize the valid operation of elevator, and extend the service life of the elevator. Secondly, it is the smart parking lot system, which can provide smart timing, and billing, and can display the quantity and geological position of idle parking spaces, and provide electronic car searching, positioning and guiding. When customers input their information on the comprehensive information platform of the hotel, the hotel information system can conduct automatic identification, and unified management. Thirdly, it is the smart monitoring system of the hotel. On the basis of safety monitoring, it has also increased anti-theft function, HD recognition function, damage-proof function, etc. as well as the function to recognize fire; besides, it is also connected to the firefighting system, and can timely provide corresponding measures.

\section{Comprehensive}

Smart hotel can provide comprehensive service for customers, and require the application of the newest information technology to realize the automatic sensitivity, timely transmission and data digging analysis of various kinds of information inside the hotel, and build the comprehensive service platform of smart hotels. Customers can understand about various kinds of information through self-service terminals, which can not only improve the customer service level of the hotel, but also improve the satisfaction degree of customers about the hotel. 
Through the comprehensive information platform of the hotel, you can know about the local weather, air quality, local map, scenery characteristics, surrounding beautiful sceneries of the hotel, delicious food, shopping, travel, entertainment and other information. Meanwhile, the comprehensive information platform of the hotel can also display the flight, train, high speed rail, bullet train, long distance bus, metro, bus and other information and line diagram. When checking out, customers can use the comprehensive information platform of the hotel to query the consumption details and bill conditions of customers. Except for the improvement of customers' satisfaction degree, the comprehensiveness of smart hotel can also realize a huge promotion of hotel management level.

\section{CONCLUSION}

Along with the constant competition among hotels and the constantly increased customers' expectation, the quality competitions of hotel design style, catering flavor, room facilities, etc. will no longer be the main contents attracting customers, while the development of science and technology will make the large-scaled application of advanced informatization technology the most valid means to attract customers. This has promoted the generation of smart hotels. Thus, hotel competition will be mainly focused on intelligence, individualization, informatization, etc., and smart hotels will be energetically developed. Hotel managers can only decrease the management cost and improve customers' satisfaction degree, reinforce the core competitiveness of the hotel, and obtain new advantages on the road of future operation through starting from the perspective of customers, expanding the smart range of hotels, and increasing smart service.

\section{ACKNOWLEDGMENT}

This paper is one of the Guilin Tourism University Scientific research fund Project (2015ZD05); also is one of the Guangxi Universities' young and middle-aged teachers Scientific research fund Project (2016LX454); And one of research results funded by Guilin Tourism University key discipline tourism management Research funding project.

Author: Xia Xu (1978- ), women, born in Nanning in Guangxi Province, Master's degree, Senior economist, and research area: Hotel management.

\section{REFERENCES}

[1] H.Y. Zhao. Smart Hotel Review [J]. Low Carbon World, 2012 (01):54.

[2] X. X. Ren. Research on the Construction and Application of the Smart Hotel Construction Evaluation Index System [D]. Thesis for Master Degree in Hebei Normal University, 2014

[3] W. L. Luo. Study on Existing Problems and Solutions in the Construction of Smart Hotels [J]. Tourism Overview, 2016 (01):84-85.

[4] L. Wang. Smart Hotel Product Design Based on Customer Experience [J]. Journal of Tianjin Sino-German Vocational Technical College, 2014(02):62-64.

[5] S. L. Chen. Developing Smart Hotels in Suzhou with the Help of Big Data [J]. Business Economy, 2014 (12): 49- 51.

[6] C. D. Zhou, J. G. Quan. Study on Smart Hotel Management [J]. China Journal of Commerce, 2018 (01): 11-12. 